Edited Book titled "Impact of Covid-19 on Indian Society: Challenges \& Opportunities"

Editors- Dr. Rimjim Borah, Dr. Bidyananda Borkakoty and Pranjal Protim Borah, Balaji Publications, 2020, ISBN-978-93-85756-99-3

Chapter-2, Pages-(9-18)

\title{
Indian Education in Pandemic Covid-19
}

\author{
By \\ Dr. Pravat Kumar Jena \\ Assistant Regional Director, \\ IGNOU Regional Centre, Bhubaneswar. \\ Email-pravat@ignou.ac.in
}

\begin{abstract}
The spread of pandemic Covid-19 has drastically disrupted every aspects of human life including education. It came as havoc for developing countries like India. It has compelled the human society to maintain social distancing and made people mandatory to sit indoor. It has significantly disrupted the education sector which is a critical determinant of economic future of a country. Many educational institutions around the world have closed their campuses and moved for online teachinglearning mode. In India, about 32 crore learners stopped to move schools/colleges and all educational activities brought to an end. The outbreak of Covid-19 has worked as a catalyst for the educational institutions to grow with digital technologies, which has never happened before. The educational institutions have managed to ensure the continuity of educational activities with digital technologies during the pandemic and are expecting the same trend to continue. This paper highlights some measures taken by Govt. of India to provide seamless education in the country during the pandemic Covid-19. Various challenges and opportunities created by Covid-19 on education are discussed. Some of the post Covid-19 trends which may allow imagining the new ways of teaching learning in India are outlined. Some fruitful suggestions are also pointed to carry out educational activities during the pandemic situation.
\end{abstract}

Keywords: Pandemic, Education, Challenges, Opportunities, India, post Covid-19

\section{Introduction}

The pandemic Covid-19 has spread over whole world and has significantly disrupted the education sector. It was first identified in Wuhan, China on December 31, 2019. First death by Covid-19 was the 61-year old man in Wuhan, China on January 11, 2020. On February 11, 2020, the World Health Organisation (WHO) proposed an official name of the virus as Covid-19, an acronym for Coronavirus disease 2019 and declared it as a pandemic on March 11, 2020. In India, the first case of the Covid-19 
pandemic was reported on 30 January 2020 in the state of Kerala who had a travel history from Wuhan, China (Wikipedia). The first death was reported on March 12, 2020 in India and the nation started the $1^{\text {st }}$ phase of lockdown on March 25, 2020. Monitoring the effects of the virus, Indian Government has been extending the lockdown period in different phases and reached at lockdown 7.0 which is effective from $1^{\text {st }}$ August to $31^{\text {st }}$ August 2020. In all the phases of lockdown starting from lockdown1.0 to lockdown 7.0, the education sector has never got any scope to start its activities. Covid-19 has affected more than 2 crores of people worldwide (WHO). According to the UNESCO report, it had impacted more than $90 \%$ of total world's student population during mid April 2020 which has reduced to nearly $67 \%$ till end of July 2020. Outbreak of Covid-19 has impacted more than 120 crores of students and youths across the planet. In India, more than 32 crores of students have been impacted by the various restrictions and the nationwide lockdown. The lockdown has compelled many educational institutions to cancel their classes, examinations, internships etc. and to choose the digital mode of education. Initially, the educators and the students were quite confused and didn't understand how to cope up with the situation of this sudden crisis that compelled closure of the educational activities. But latter on all realized that the lockdown has taught so many lessons to manage with the emergence of such pandemics. Thus, Covid-19 has created many challenges and opportunities for the educational institutes to strengthen their technological knowledge and infrastructure (Pravat, 2020a). The lockdown has given them a ray of hope for teachers and students to continue their educational activities through online. The teachers assigned work to students via internet, delivered lectures through live video conferencing using different Apps like Zoom, Google meet, Facebook, Youtube, and Skype etc. In a nation like China that practices a considerably more centralization system, a change to digital learning may be simpler. Even in a nation like the U.S.A, there are some low-pay students who don't approach broad bands and unable to use computerized learning arrangement. The same is the situation that happens with India where not every student is well equipped with the high-speed internet and digital gadgets and are along these lines of suffer (Study Abroad Life). Numerous advanced educational institutions in India are not also equipped with digital facilities right now to cope up with sudden change from traditional education set up to the online education system.

\section{Objectives}

The present study is focused on the following objectives:

- To enlighten various measures taken by Govt. of India for education sector during this pandemic.

- To highlight various challenges and opportunities created by Covid-19 on education.

- To enlist post Covid-19 trends of education.

- To put some effective suggestions for continuing educational activities during the pandemic Covid-19 situation.

\section{Methodology}


Data and information presented in current study are collected from various reports prepared by national and international agencies on Covid-19 pandemic. As it is not possible to go outside for data collection due to lockdown, information are collected from different authentic websites, journals and e-contents relating to various impact of Covid-19 on educational system of India.

\section{Measures taken by Govt. of India for Education during Covid-19}

Government of India has taken number of preventive measures to prevent spread of pandemic Covid-19. The union government declared a countrywide lock-down of all educational institutions on 16 March 2020. Central Board of Secondary Education (CBSE) postponed all examinations of secondary and higher secondary schools on March 18, 2020 all over the country. The Union Public Service Commission (UPSC) postponed the interview for the Civil Services Examination 2019 also (Wikipedia). Similarly the most of the state Governments and other educational boards postponed examinations due to outbreak of Covid-19. Almost all state government ministries have taken measures to ensure that the academic activities of schools and colleges do not hamper during the lockdown period. They have instructed the schools to hold all their classes online. The lockdown has accelerated adoption of digital technology. It has provided a chance to develop new and improved professional skills/knowledge through online learning in more efficient and productive way. Online learning is the best solution during this pandemic Covid-19 situation (Pravat, 2020b). So, the digital India vision of the government is emerging as a vital tool for solving the present crisis due to Covid-19. The Ministry of Human Resource Development (MHRD) has made several arrangements, including online portals and educational channels through Direct to Home TV, Radios for students to continue learning. ICT initiative of MHRD (e-Broucherhttps://mhrd.gov.in/ict-initiatives ) is a unique platform which combines all digital resources for online education. Some of the digital initiatives of MHRD \& UGC for secondary as well as higher education during Covid-19 are listed as below:

\section{Secondary Education}

- Diksha portal contains e-Learning content for students, teachers, and parents aligned to the curriculum, including video lessons, worksheets, textbooks and assessments. Under the guidance of its national boards of education (CBSE) and NCERT, the content has been created by more than 250 teachers who teach in multiple languages. The app is available to use offline. It has more than 80,000 e-Books for classes 1 to 12 created by CBSE, NCERT in multiple languages. The app can be downloaded from IOS and Google Play Store. Website: https://diksha.qov.in or https://seshaqun.qov.in/shaqun

- e-Pathshala is an e-Learning app by NCERT for classes 1 to 12 in multiple languages. The app houses books, videos, audio, etc. aimed at students, educators and parents in multiple languages 
including Hindi, Urdu, and English. In this web portal NCERT has deployed 1886 audios, 2000 videos, 696 e-Books and 504 Flip Books for classes 1 to 12 in different languages. Mobile App is available. Website: http://epathshala.nic.in or http://epathshala.qov.in.

- National Repository of Open Educational Resources (NROER) portal provides a host of resources for students and teachers in multiple languages including books, interactive modules and videos including a host of STEM-based games. Content is mapped to the curriculum for classes 1-12, including aligned resources for teachers. Website: http://nroer.qov.in/welcome

\section{Higher Education}

- e-GyanKosh (http://egyankosh.ac.in/) is a National Digital Repository to store and share the digital learning resources which is developed by the Open and Distance Learning Institutions of India. Items in eGyanKosh are protected by copyright, with all rights reserved by Indira Gandhi National Open University (IGNOU).

- Gyandarshan (http://www.ignouonline.ac.in/gyandarshan/) is a web based TV channel devoted to educational and developmental needs for Open and Distance Learners.

- Gyandhara (http://ignouonline.ac.in/Gyandhara/) is an internet audio counseling service offered by IGNOU. It is a web radio where students can listen to the live discussions by the teachers and experts on the topic of the day and interact with them through telephone, e-mail (gyandhara@,ignou.ac.in ) and through chat mode.

- Swayam is the national online education platform hosting 1900 courses covering both school (classes 9 to 12) and higher education (under graduate, post graduate programs) in all subjects including engineering, humanities and social sciences, law and management courses. The unique feature is that, it is integrated with the conventional education. Credit transfers are also possible for SWAYAM courses (max. 20\%). Website: https://swayam.gov.in/

- Swayam Prabha has 32 DTH TV free channels transmitting educational contents on 24 x 7 basis. The channels cover both school education (classes 9 to 12) and higher education (undergraduate, postgraduate, engineering Out-of-school children, vocational courses and teacher training) in arts, science, commerce, performing arts, social sciences and humanities subjects, engineering, technology, law, medicine, agriculture. Website: https://swayamprabha.gov.in/

- e-PG Pathshala is for postgraduate students. Postgraduate students can access this platform for ebooks, online courses and study materials during this lockdown period. The importance of this platform is that students can access these facilities without having internet for the whole day. Website: https://epgp.inflibnet.ac.in/

\section{Challenges created by Covid-19 for Education}


Education sector has suffered a lot due to the outbreak of Covid-19. Pandemic Covid-19 has created many challenges for all stakeholders of education especially during the lockdown periods and some of them are as pointed below:

- Digital literacy and Technical issues: During lockdown period for Covid-19, the educational institutions are depending mostly on use of online platforms which becomes very difficult for the computer illiterate learners to manage. Some learners may face difficulty to use online platforms due to poor technical knowledge in using gadgets and some may suffer due to poor internet connectivity in their locality (Pravat, 2020a). The lockdown has hit the poor students very hard in India as most of them are unable to explore online learning according to various reports.

- Self motivation and Social Status: Motivation of the learners is highly necessary to explore the facilities of using online support services during the pandemics which is lacking in some learners. Some financially weaker section may not afford the purchase the required technical gadgets or high speed internet services for online learning. Some disadvantaged learners may also suffer in accessing online support services provided by the educational institutions during the pandemics (Pravat, 2020a).

- Unprepared teachers/students for online education- Not all teachers/students are good at it or at least not all of them were ready for this sudden transition from face to face learning to online learning (Pravat, 2020c). Most of the teachers are just conducting lectures on video platforms such as Zoom, Google meet etc. which may not be real online learning without any dedicated online learning platform.

- Unemployment: Most of the recruitment got postponed due to Covid-19. The pass out students may not get their job outside India due to restrictions caused by Covid-19. Many Indians might have returned home after losing their jobs overseas and many students who have already got jobs through campus interviews may not be able to join their jobs due to lockdown (Pravat, 2020c). So, unemployment rate is expected to be increased due to this pandemic. The Centre for Monitoring Indian Economy's estimates on unemployment shot up from $8.4 \%$ in mid-March to $23 \%$ in early April and the urban unemployment rate to $30.9 \%$ (Educationasia.in). When the unemployment increases then the education gradually decreases as people struggle for food rather than education.

- Loss of nutrition for poor children due to School closure: Mid day meals is a school meal programme of the Government of India which is designed to provide better the nutritional food to school-age children nationwide. The closure of schools has serious implications on the daily nutrition of students as the mid-day meal schemes have temporarily been shut (Pravat, 2020c). Various studies have pointed out that mid-day meals are also an important contributing factor for increased enrolment in the schools. 
- Access to global education: The pandemic has significantly disrupted the higher education sector. A large number of Indian students who are enrolled in many Universities abroad, especially in worst affected countries are now leaving those countries and if the situation persists, in the long run, a there will be a significant decline in the demand for international higher education.

\section{Opportunities created by Covid-19 for Education}

Though the outbreak of Covid-19 has created many challenges for education, it has created many opportunities for transformation of traditional system to a new system of education especially during the lockdown period which may be pointed as below:

- Enhanced Blended Learning mode: Covid-19 has accelerated adoption of digital technologies to deliver education. Educational institutions moved towards blended mode of learning. It encouraged all teachers and students to become more technology savvy (Pravat, 2020c). New ways of delivery and assessments of learning opened immense opportunities for a major transformation in the area of curriculum development and pedagogy. It also gives access to large pools of learners at a time.

- Accelerated the use of Learning Management Systems: Use of learning management systems by educational institutions became a great demand. It opened a great opportunity for the companies those have been developing and strengthening learning management systems for use educational institutions (Misra, 2020).

- Encouraged collaborative work- There is a new opportunity where collaborative teaching and learning can take on new forms. Collaborations can also happen among faculty/teachers across the world to benefit from each other (Misra, 2020).

- Enhanced Digital Learning mode-The pandemic has created a massive rise in teleconferencing, virtual meetings, webinars and e-conferencing opportunities. The pandemic situation induced people to learn and use digital technology and resulted in increasing the digital literacy.

- Improved the use of electronic media for sharing information: Learning materials are shared among the students easily and the related queries are resolved through e-mail, SMS, phone calls and using different social Medias like WhatsApp or Facebook (Pravat, 2020c).

- Enhanced demand for Open and Distance Learning (ODL): During the pandemic situation most of the students preferred ODL mode as it encourages self-learning and provides opportunities to learn from diverse resources with customized learning as per their needs.

\section{Post Covid-19 trends of Education}


Covid-19 may lead towards a better tomorrow and new technologies will certainly challenge the traditional paradigms such as classroom lectures, modes of learning and modes of assessment. The new trends may allow the education sector to imagine new ways of teaching learning and some trends (Pravat, 2020d) may be pointed as below.

1. Personalised learning may improve: Learning may not be confined to classes or to any specific boundaries. Students may pursue their learning in the new paradigm as per their choice.

2. Attendance of students may slow down: Many parents may be reluctant to send back their children to schools/colleges suddenly after the end of lockdown. Some poor family parents who have lost their livelihood during the pandemic may not be able to afford the expenditure to send their children to institutions. This may lead to home education for another few months.

3. Student mobility for higher study may reduce: Student safety and well-being issues are important deciding factors for students and their parents for movement to international institutions for higher study. Most of the parents will prefer to find workable alternatives closer to their home and may restrict for less movement within the country due to the pandemic. So, the national and international student movement may be diminished.

4. Social distancing in education may continue. Everyone will try to continue social distancing, avoid handshaking, hugging, personal greeting and intimacy for a long time. Social restrictions may constraint the fun \& joy of campus life. Sports, Gyms, tournaments may be in low gear for a longer period resulting less physical activities of students.

5. Education may continue with different shifts per day- The concept of social distancing may imply lesser students in each class. So, education may continue in different shifts per day which may put more pressure on the teaching and administrative staff of the institution to manage.

6. May create inequality between privileged and unprivileged students- Learners from lowincome families and disadvantaged groups are the more likely to suffer as they may not afford the required technical facility for online learning. It will widen the gap between privileged and unprivileged learners creating inequality.

7. Education may run with technology-More and more students will depend on technology and digital solutions for teaching learning, entertainment and connecting themselves with the outside world. Students will use internet technology to communicate virtually with their teachers and fellow learners through E-mail, WhatsApp, Videoconference, Instant message, webinar or any other tool.

8. Artificial Intelligence may take lead role in education. Artificial Intelligence (AI) may help teachers to deal with assessment, evaluation, preparing mark-sheets and monitoring the performance of each student easily. AI may use digital platform extensively to reduce burden of examiner in handling examination and evaluation systems. If these activities are made simpler, 
the academicians would be able to concentrate more on course development, qualitative teaching-learning and skill development.

9. Demand for Open and Distance Learning (ODL) may grow. Covid-19 has forced the human society to maintain social distancing and created more challenges to continue teaching learning. To meet these challenges there is more demand for ODL and online modes of education and the same trend may continue in future also.

10. Blended learning may play an important role. Blended learning combines both face to face and online learning modes. Covid-19 has accelerated adoption of digital technologies to deliver education and encouraged the educational institutions to move towards blended mode of learning. The traditional face to face mode with post Covid-19 digital mode will lead the education towards blended mode of education and it may transform the structure of the education system.

11. Debt crisis for students may rise. In India, lots of students or their parents take education loans for higher education. If the unemployment situation continues, student debt crises may rise and create serious issue. Students may face increased stress, anxiety and depression due to their student loans.

12. Unemployment rate is expected to be increased. There is no recruitment in Govt. sector and fresh graduates fear withdrawal of their job offers from private sectors because of the pandemic Covid-19. Many are losing their jobs overseas due to Covid-19. The fresh students who are likely to enter the job market shortly may face difficulty in getting suitable employment.

\section{Suggestions}

1. Online platforms with enhanced safety and safeguarding measures, especially for virtual learning tools should be ensured. Government/educational institutions should also create awareness on online education with safety measures for learners and take measures to create awareness on cyber security(Pravat, 2020b)

2. Institutions should provide proper academic and psychological support to the students during the pandemic. Integrated technology platform should be created for learners which may include digital services, web based services and broad cast based services so that learners can use as per their own choices.

3. India should develop creative strategies to ensure that all children must have sustainable access to learning during pandemics. The Indian policies must include various individuals from diverse backgrounds including remote regions, marginalised and minority groups for effective delivery.

4. Immediate measures may be taken to lessen the effects of the pandemics on job offers, internship programs, and research projects. 
5. Across the globe, Indian traditional knowledge is well known for its scientific innovations, values and benefits to develop sustainable technologies and medicines and this knowledge systems in different fields should be integrated with a present-day mainstream higher education system.

6. Govt and educational institutes should plan to continue the educational activities maintaining social distancing. 30-40\% students and teachers may attend schools/colleges in two shifts per day to carry on educational activities by obeying guidelines for Covid-19 (Pravat, 2020d).

7. Some significant issues associated with distance learning strategies like the availability and access to digital devices with internet connectivity, the need for safe learning spaces, creating capabilities for teachers, families and students to operate and navigate digital devices, engaging lesson plans for disabled students and other marginalised groups should be addressed by Govt. and the stakeholders.

\section{Conclusions}

Education sector of India is immensely impacted by Covid-19. Govt. of India has taken many fruitful measures to meet the challenges created by Covid-19. Challenges created by Covid-19 have also opened various opportunities in education sector. The Indian Govt. and different stakeholders of education have explored the possibility of teaching-learning by adopting different digital technologies to cope up with the crisis. As, India is not yet fully equipped to make education reach all corners of the nation via digital platforms, the less privileged students may suffer due to the present choice of digital platforms. But, Universities and the Government of India are relentlessly trying to come up with a solution to resolve this problem. The priority should be to utilise digital technology to create an advantageous position for crores of young students in India. India should develop creative strategies to ensure that all children must have sustainable access to learning during pandemics. The post Covid-19 education is expected to be the digital mode of education which may start a new era in education sector of India.

\section{References}

1. WHO: WHO Coronavirus Disease (COVID-19) Dashboard. Retrieved on July 25, 2020 from https://covid19.who.int/

2. Wikipedia: Covid-19 Pandemic in India. Retrieved on July 25, 2020 from https://en.wikipedia.org/wiki/COVID-19 pandemic in India

3. UNESCO: COVID-19 Educational Disruption and Response. Retrieved on July 30, 2020 from https://en.unesco.org/covid19/educationresponse

4. Pravat Ku. Jena (2020a): Challenges and Opportunities created by Covid-19 for ODL: A case study of IGNOU. International Journal for Innovative Research in Multidisciplinary Filed, Vol-6, Issue5, Pg. 217-222. 
5. Study Abroad Life (2020): How Covid-19 will affect the Indian education system. Retrieved on July 25,2020 from https://www.studyabroadlife.org/how-covid-19-will-affect-the-indian-education-system/

6. Pravat Ku. Jena (2020b): Online learning during lockdown period for covid-19 in India. International Journal of Educational Research, Vol-9, Issue- 5(8), Pg.82-92.

7. Wikipedia: Education in India. Retrieved on July 26, 2020 from https://en.wikipedia.org/wiki/Education in India

8. Pravat Ku. Jena (2020c): Impact of Pandemic COVID-19 on Education in India. International Journal of Current Research Vol.12, Issue-7, Pg.12582-12586.

9. MHRD notice (20 March, 2020): COVID-19 Stay Safe: Digital Initiatives. Retrieved on July 28, 2020 from https://www.mohfw.gov.in/pdf/Covid19.pdf

10. Educationasia.in (29 April 2020): The Impact of COVID-19 on Education and Education Sectors, Know Here. Retrieved on July 28, 2020 from

https://educationasia.in/article/the-impact-of-covid-19-on-education-and-education-sectors-know$\underline{\text { here }}$

11. Pravat Ku. Jena (2020d): Impact of Covid-19 on higher education in India. International Journal of Advanced Education and Research, Vol.5, Issue-3, Pg-77-81.

12. Misra Kamlesh (May 12, 2020). Covid-19: 4 negative impacts and 4 opportunities created for education. Retrieved on July 28, 2020 from https://www.indiatoday.in/education-today/featurephilia/story/covid-19-4-negative-impacts-and-4opportunities-created-for-education-1677206-2020-05-12 